\title{
LA COMUNICACIÓN DEL PATRIMONIO: VALORACIÓN DE LOS PROCESOS COMUNICATIVOS EN MUSEOS DE ASTURIAS
}

\section{The communication of heritage: Assessment of the Communicative Process in Museums of Asturias}

Miguel Ángel SUÁREZ SUÁREZ

Profesor Asociado. Universidad de Oviedo, España

E-mail: migsrz@gmail.com

(1D http://orcid.org/0000-0003-4659-2040

Roser CALAF MASACHS

Profesora Titular. Universidad de Oviedo, España

E-mail: rcalaf@uniovi.es

(1D http://orcid.org/0000-0001-5066-9245

M. ${ }^{a}$ del Carmen FERNÁNDEZ RUBIO

Profesora Titular. Universidad de Oviedo, España

E-mail: mcfrubio@uniovi.es

(D) http://orcid.org/0000-0001-5768-2290

Fecha de recepción del artículo: 01/12/2016

Fecha de aceptación definitiva: 16/12/2016

\begin{abstract}
RESUMEN
La comunicación del patrimonio, especialmente la que tiene lugar en los museos, posee unas características peculiares que lo convierten en un proceso complejo. La diversidad de objetos, los discursos que se generan en torno a ellos y las interacciones entre las distintas audiencias convierten a cada museo en un caso único, dificultando la construcción de teorías que ayuden a comprender y mejorar los procesos comunicativos en los contextos museales. En este sentido, partiendo de estudios previos y a través de una investigación basada en la observación directa y el seguimiento de visitas guiadas, se analizan siete museos de Asturias, prestando especial atención a la distribución espacial, la museografía y las intervenciones de los educadores y el público escolar. Los resultados ponen de manifiesto que los museos están haciendo esfuerzos notables por establecer modelos de comunicación multidireccional, diseñando con coherencia los espacios expositivos, la museografía de objetos y las explicaciones de los educadores. Sin embargo, todavía existen algunos problemas que impiden hablar de un diálogo pleno entre la escuela y el museo, lo que acaba limitando la eficacia comunicativa del mensaje sobre el patrimonio.
\end{abstract}

Palabras clave: Comunicación; Museos; Patrimonio Cultural; Educación patrimonial.

\begin{abstract}
Communicating of heritage, especially in museums, is a complex process due to certain particularities. Each museum is unique because of the diversity of objects, the discourses generated and the interactions between different audiences. It makes it difficult to build theories which help to understand and improve the communicative process with-
\end{abstract}


in the museum context. In this way, from prior studies and through both a direct observation and monitoring of the guided visits, this work shows the analysis of 7 museums from Asturias, focusing on the spatial distribution, the museography and the interventions of the teachers and students. The results show that museums are making an effort to set up multidirectional communication models, doing a coherent design between exhibition spaces, the objects' museography and the teachers' explanation. Nevertheless, there are some problems which impede a full connection between the school and the museum, which limit the effective communication of the message about heritage.

Key words: Communication; Museums; Cultural Heritage; Heritage Education.

\section{INTRODUCCIÓN}

Desde que el museo inició el largo trayecto desde el simple almacenamiento decimonónico hacia las tareas de conservación, investigación y divulgación asentadas desde finales de la década de 1960, la comunicación ha ido adquiriendo cada vez mayor protagonismo. El desarrollo de Internet y la casi omnipresencia de las redes sociales han complicado el panorama creando dos ámbitos que, aun interrelacionados por formar parte del mismo todo (museos y patrimonio), están bien diferenciados: la comunicación digital o virtual y la comunicación presencial. El primero de ellos ha gozado en los últimos años de un especial interés por parte de los investigadores, que han tratado de arrojar luz sobre la implantación y el uso comunicativo de la tecnología por parte de las instituciones museísticas. A este respecto puede avanzarse una conclusión general: aún queda mucho camino por recorrer.

Algunos estudios se centraron, en un primer momento, en el análisis de las páginas web de los museos, teniendo en cuenta criterios como la interactividad, la información proporcionada y la potencialidad didáctica. Entre los problemas detectados, pueden destacarse que la mayoría de las webs que han sido objeto de análisis tienen un carácter eminentemente informativo, con un bajo nivel de interactividad -asíncrono en muchos casos- y los aspectos educativos poseen aún un carácter incipiente (Ibáñez, Correa y Jiménez, 2003, p. 435). De igual forma, la selección de contenidos suele hacerse superponiendo los criterios estéticos y monumentalistas a los didácticos (Cuenca y Estepa, 2004, p. 8) y, en definitiva, el objetivo de las webs parece ser cuantitativo -atraer al mayor número posible de visitantes, lo que sin duda es importante-, pero olvidando la vertiente cualitativa -atraer a los destinatarios de acciones educativas específicas- (Fontal, 2004, p. 187). Por otro lado, también se ha señalado la importancia que posee la formación en didáctica a la hora de diseñar un producto comunicativo que combine la función informativa de la web con el aprovechamiento de su potencial didáctico, posible mediante una adecuada selección de contenidos y materiales (Calaf y Suárez, 2011, pp. 24-30).

En cualquier caso, conviene tener presente que la tecnología avanza a un ritmo acelerado y se están produciendo importantes avances en este sentido; y, por otro lado, los problemas de interactividad están encontrando una solución accesible gracias al desarrollo y proliferación de las redes sociales, que permiten una comunicación multidireccional constante entre el museo y los visitantes. Sin embargo, algunos estudios revelan que la situación, aún hoy, dista de ser la deseable. Así, a pesar de las posibilidades comunicativas de las redes sociales, no se han desarrollado protocolos estables de comunicación, no se incentiva convenientemente la participación del público y sigue siendo necesaria la implementación de estrategias que integren no solo información sobre el propio museo, sino también enlaces a otros recursos e instituciones (Cordón y González, 2016).

Pese a todo, el ámbito digital solo es una parte del complejo entramado que conforma la comunicación del patrimonio cultural en los museos. Lógicamente el mayor peso comunicativo, tanto desde el punto de vista cuantitativo, como cualitativo, tiene lugar a través de las interacciones que se producen 
dentro del propio museo durante la visita. Esto constituye un ámbito de estudio sobre el que, como afirma Martín Cáceres (2012, p. 112) todavía no se ha investigado lo suficiente. No obstante, contamos con trabajos que han orientado sus esfuerzos a desvelar las concepciones subyacentes tras los discursos que se generan en torno al patrimonio (Estepa, 2013). Destaca para el caso que aquí se aborda el estudio sobre los gestores del patrimonio (Martín y Cuenca, 2011), especialmente lo referido a los procesos comunicativos entre el museo y sus visitantes. A este respecto, no deja de ser significativo que, según lo declarado por los gestores entrevistados, la mayoría de las actividades desarrolladas por los museos (un 48,5\%) respondían a un modelo de comunicación unidireccional, en el cual el museo expone y el visitante solo escucha; en menor medida (un 36,4\%) se desarrollaba una comunicación bidireccional y solo en un 12,1\% conseguía desarrollarse un modelo de comunicación multidireccional (ibídem). En opinión de los autores,

Se aprecia una escasez de ideas, quedando palpable la poca o casi nula importancia que se da al proceso educativo y de difusión en estas instituciones [...] Estos resultados vienen a demostrar que poseen una alta formación disciplinar sobre el patrimonio, pero nula o muy escasa formación didáctica, hacia la que salvo excepciones muestran poco interés. (Martín y Cuenca, 2011, p. 118).

Si los propios gestores no perciben las limitaciones de las actividades que programan, es evidente que nos encontramos ante un problema comunicativo importante. En este sentido, Martín Cáceres (2012, pp. 116-119) realiza un interesante trabajo profundizando en los elementos que juegan su papel en la comunicación patrimonial del museo: los entes participantes, que como es lógico hacen referencia al personal del museo (emisores) y a los usuarios (receptores); el lenguaje, a través del patrimonio expuesto y el planteamiento didáctico de las actividades; y el contexto que ubica al patrimonio espacial, temporal y socialmente. En relación con lo anterior, Calaf (2009) señala como punto fundamental la convergencia de todos los elementos comunicativos en torno a la exposición museográfica, destacando cómo la organización de los espacios y los objetos, así como la información que se aporta sobre ellos (discursos de los educadores, paneles, audiovisuales...), conforman un lenguaje propio del que se desprende la idiosincrasia del museo. De modo que las prácticas del museo, desde la exposición hasta las explicaciones de los educadores, han de considerarse como un media, un producto comunicativo que produce uno u otro efecto en el receptor en función de su planteamiento (Davallon, 1999). Pero lógicamente, en ese efecto también interviene el papel de los receptores, en tanto que su relación con los bienes culturales u objetos patrimoniales va a influir, de manera determinante, en los significados que se desprendan del mensaje sobre el patrimonio (Eco, 1962 y 2000). Valorar cómo se interrelacionan estos elementos y el tratamiento que de ellos se hace es, por tanto, necesario para mejorar los procesos comunicativos del museo. Por supuesto, es cierto que existen otros factores influyentes que tienen que ver con limitaciones presupuestarias, inestabilidad de las plantillas, etc.; sin embargo, se han excluido de este escrito por razones de espacio.

\section{DiSEÑO DE LA INVESTIGACIÓN}

Se ha planteado una investigación evaluativa, externa y formativa centrada en los procesos comunicativos que tienen lugar en el museo. Se han seleccionado siete museos de Asturias de temática histórica mediante un muestreo intencionado que responde a los criterios de representatividad territorial y diversidad patrimonial: el Parque de la Prehistoria (Teverga), el Centro de Arte Rupestre de Tito Bustillo (Ribadesella), las Termas Romanas de Campo Valdés (Gijón), el Museo del Ferrocarril de 
Asturias (Gijón), el Museo de la Siderurgia (Langreo), el Museo Marítimo (Luanco) y el Museo Etnográfico del Oriente de Asturias (Porrúa).

Para el desarrollo de la investigación se ha optado por un enfoque cualitativo, dado que permite un mayor grado de profundización en los aspectos a valorar (Angrosino, 2012; Banks, 2010; Gibbs, 2012). Asimismo, el modelo de investigación combina un diseño analítico e interactivo (McMillan y Schumacher, 2005) para dar cuenta de los dos objetivos principales de este trabajo: por un lado, realizar una lectura e interpretación del mensaje que transmite el museo a través de su discurso museográfico, para lo que será necesario disponer de un marco teórico sólido; y por otro lado, valorar las interacciones que se producen en torno a ese mensaje, extrayendo información de situaciones reales en las que interviene tanto el personal de los museos, como los visitantes. Esto requiere el empleo de estrategias interactivas para discriminar la información válida entre la multiplicidad de situaciones que pueden aparecer durante el trabajo de campo (Flick, 2004). Así, se han planificado varias sesiones de observación directa y sistematizada en los distintos museos, utilizando una plantilla de análisis conforme a los criterios que se explicitarán posteriormente.

No obstante, no debe olvidarse que en la investigación cualitativa entra en juego, de forma determinante, la subjetividad del investigador, lo que hace necesario el desarrollo de estrategias para compensarla y transformarla en lo que Erickson (cit. por McMillan y Schumacher, 2005, p. 419) denominó «subjetividad disciplinada». De modo que, a través de ciertos procedimientos interpersonales como la triangulación, es posible reforzar la validez de la investigación. En este sentido, en el trabajo de campo han participado tres observadores, cuyas visiones se contrastaban al finalizar cada sesión de trabajo. Cabe señalar que dos de ellos tenían experiencia investigadora en el ámbito de la Didáctica del Patrimonio, mientras que el tercero, sin experiencia, ha ofrecido al estudio una visión desde la perspectiva de un visitante más. Esta última visión resulta útil para obtener un juicio más natural, rectificando la deformación profesional fruto de una experiencia continuada que puede magnificar algunos detalles y descartar otros que también pueden ser importantes. A ellos se suman dos expertos, profesores de Universidad, que supervisaron todo el estudio actuando como jueces que promovieron un necesario proceso de meta evaluación, siguiendo la propuesta de San Fabián (2016).

\section{FUNDAMENTACIÓN TEÓRICA E INSTRUMENTOS PARA EL ANÁLISIS}

La comunicación del patrimonio en los museos emplea un lenguaje particular cuya principal característica es la heterogeneidad, tanto por la propia naturaleza compleja y diversa del patrimonio, como por la variedad de actores que intervienen en el proceso. Esta situación, claramente, dificulta su estudio; mucho más si lo que se pretende no es únicamente el análisis de la comunicación en sí misma, sino comprobar cómo puede servir a determinados fines, en este caso, a la enseñanza-aprendizaje con el patrimonio. De modo que es preciso definir qué elementos comunicativos van a centrar el estudio y tratar de desvelar qué papel desempeñan en una situación de interacción real, concretamente durante las visitas guiadas con estudiantes.

\subsection{EL PAPEL DEL EMISOR}

En lo que respecta al emisor (el museo), no cabe duda de que su principal interés es hacer inteligible y atractivo el mensaje sobre los referentes patrimoniales que custodia. Ahora bien, al afrontar su análisis desde el punto de vista de las visitas escolares deben tenerse en cuenta las dos dimensiones que confluyen en este mensaje: la objetual y la humana. La primera de ellas constituye la base, los cimientos que sustentan todo el discurso sobre el patrimonio. Aquí entran en juego elementos como la distribución de los espacios, la selección y ubicación de los objetos, así como la información textual y 
gráfica que se aporta sobre ellos mediante cartelas, paneles, audiovisuales, etcétera. Por su parte, en la dimensión humana entran en juego, lógicamente, los discursos de los educadores y su interacción con los visitantes, en este caso docentes y alumnado.

Teniendo en cuenta estas dos dimensiones, es necesario considerar una serie de factores que guiarán la evaluación. Con respecto a la distribución espacial, parece claro que el objetivo deseable es lograr una movilidad efectiva por el museo. Dicha efectividad dependerá de que el visitante pueda conocer y comprender cómo se organiza el espacio, qué itinerarios se pueden seguir, qué temáticas o áreas se pueden visitar..., sin olvidar la ubicación de los objetos, que han de ser significativos y no ofrecer sensación de caos o abigarramiento. En definitiva, brindar al usuario la posibilidad de organizar la visita, conociendo en todo momento de qué opciones dispone mediante los indicadores oportunos, que a su vez pueden guiarle a través de itinerarios estructurados y coherentes con el discurso que el museo quiere transmitir (Bitgood, 2013). Se trata de un factor importante, no solo porque una distribución espacial lógica es esencial para construir un discurso museográfico comprensible, sino también porque facilita que el visitante pueda centrarse en los contenidos y no tanto en dilucidar - $\mathrm{O}$ adivinar- cuál es el siguiente paso en el recorrido (Bitgood, 2014). Por tanto, que el museo proporcione información detallada sobre los posibles itinerarios a seguir, ya sea mediante señalética o folletos, debe establecerse como un criterio de calidad en la evaluación.

Ahora bien, como se ha señalado, una adecuada distribución espacial no es un fin en sí misma, sino uno de los medios para favorecer la comprensión de los contenidos que el museo quiere transmitir. Así, a la movilidad efectiva le sigue el que es uno de los elementos comunicativos centrales: el lenguaje y su uso por parte del museo. Evidentemente, gran parte del mensaje museográfico recae, en primera instancia, en los recursos textuales y gráficos (desde los paneles, hasta los audiovisuales), que pueden contribuir enormemente a clarificar algunos significados del patrimonio expuesto. Sin embargo, desde hace tiempo algunos autores han señalado cómo la cuestión es más compleja que la simple presencia o no de estos recursos. La forma en que está planteado el guion (descriptivo, interpretativo, formulando preguntas, etc.), la tipografía, la ubicación... son factores que irremediablemente van a influir en la lectura/visionado de los paneles y audiovisuales, y por tanto en la comprensión del mensaje (Hirschi y Screven, 1988; Screven, 1992). Stephen Bitgood sintetizó con elocuencia los principales problemas en relación con este ámbito:

Podría decirse que, desde los primeros pasos de los museos, los paneles se han utilizado como instrumentos de tortura sobre los indefensos visitantes. Una primera forma de tortura exige permanecer de pie largos períodos de tiempo leyendo paneles con cientos de palabras. Otra forma obliga a los visitantes a leer palabras imposibles de ver a causa de la pobre iluminación. En una tercera forma de tortura los visitantes quedan a merced de la jerga técnica y un vocabulario complicado. Otras ocasiones, los visitantes se ven obligados a contorsionar sus cuerpos (estirar el cuello, doblarlo, etc.) para poder leer. Una quinta forma de tortura es mostrar caracteres tan pequeños, que serían necesarias unas lupas para leerlos. Otra forma es obligar al visitante a leer caracteres descoloridos o borrosos por el paso del tiempo. La séptima forma consiste en hacer adivinar a los visitantes de qué trata la exposición omitiendo totalmente los paneles o proporcionando paneles que dificultan la identificación de los objetos. La lista podría seguir y seguir [...]. (Bitgood, 1990, p. 115). 
De lo anterior puede inferirse que minimizar la percepción del esfuerzo es un criterio importante a la hora de diseñar una exposición, dado que un mayor esfuerzo conlleva una menor motivación para el visitante $y$, por tanto, una comunicación ineficaz que no llega plenamente al receptor. Así, en la evaluación habrán de considerarse cuestiones como la longitud de los textos o vídeos, el tamaño y el color de la tipografía, su contraste con el fondo (visibilidad y sonido en el caso de audiovisuales) y su ubicación.

Finalmente, el papel del emisor finaliza con la dimensión humana de la comunicación en el museo. En efecto, el desempeño profesional de los educadores y educadoras constituye el elemento clave que, desde el punto de vista educativo, hilvana todo el discurso museográfico haciéndolo accesible para el visitante (Calaf y Fontal, 2010). Sobre este asunto, algunos trabajos (Gutiérrez y Calaf, 2013; Suárez, Gutiérrez, Calaf y San Fabián, 2013; Suárez, Calaf y San Fabián, 2014), a través de un estudio sistemático en diversos contextos museísticos, sugieren algunos elementos que consideran básicos para un correcto ejercicio comunicativo y didáctico en los educadores de los museos. Así, se destaca la importancia de que muestren seguridad en sus explicaciones, lo que denota dominio del contenido y rigurosidad conceptual; de realizar preguntas para estimular el diálogo con los visitantes, retroalimentando su discurso con las nuevas aportaciones que puedan surgir; y de tratar de conectar con el mundo experiencial de los visitantes, como un medio de incrementar la significatividad de los contenidos y potenciar su implicación en el desarrollo de la actividad. Asimismo, se tienen en cuenta otros factores como el uso que hacen de los recursos comunicativos: si apoyan o no sus explicaciones en los paneles y/o audiovisuales, si conceden un tiempo para la lectura o visionado de los mismos, etc.

\subsection{EL PAPEL DEL RECEPTOR}

Para culminar la evaluación de la comunicación en el museo es necesario contemplar también el papel de los receptores. En este sentido, una gran parte de los estudios se ha encaminado a desvelar el impacto que la exposición tiene en los visitantes a través de los estudios de público, cuyas bases teóricas y metodológicas beben de Screven (por ejemplo 1976 y 1986) y Shettel (1988 y 1989). Sin embargo, cabe señalar que, desde el punto de vista educativo y teniendo como referencia las visitas escolares, el proceso comunicativo se extiende más allá de propio contexto museal.

El público escolar siempre entraña una complejidad añadida, que deriva de su condición de público cautivo (esto es, que no acude por voluntad propia, sino como parte de una actividad programada por terceros), lo que puede llevar a una menor receptividad con respecto al mensaje y, en consecuencia, a una merma de la eficacia comunicativa. Es necesario, pues, que los escolares desempeñen un papel más activo para interpretar y asimilar el mensaje sobre el patrimonio, para lo cual es interesante que utilicen la información para elaborar algún producto (trabajo, exposición, etc.) en el que, precisamente, deban analizar y reinterpretar ese mensaje (De Troyer, 2005; Asensio, Asenjo y Rodríguez, 2011). Esta es la principal razón por la que, en estos casos, la comunicación debe entenderse necesariamente como un diálogo fruto de una responsabilidad compartida entre el museo y la escuela (Suárez, 2014). A este respecto, observar el papel desempeñado por los docentes y los estudiantes durante la visita, puede darnos algunas pistas sobre sobre si existe o no ese diálogo: cómo interactúan con los educadores, si formulan preguntas o no, si los docentes intervienen en algún momento para referirse al trabajo realizado en el aula... son elementos útiles a considerar durante la evaluación (Calaf, San Fabián, Suárez y Martín, 2016).

Todos estos criterios se han incluido en una plantilla de análisis (adjuntada como anexo), readaptada de la que se elaboró para el proyecto Evaluación Cualitativa de Programas Educativos en Museos Españoles (Suárez, et al., 2013). Esta última, a pesar de su exhaustividad, reveló ciertos problemas de operati- 
vidad dada su extensión y nivel de complejidad, lo que dificultaba su uso durante el trabajo de campo. Por ello, aunque se han mantenido sus elementos básicos, se ha optado por modificar el patrón de evaluación, estableciendo cuatro niveles de valoración en función del grado de cumplimiento de cada uno de los indicadores a observar: cumplimiento pleno, cumplimiento parcial (aquellos que solo se cumplen en algunos casos), no cumplido y no aplicable. Este último grado será de utilidad de cara a la validez de la plantilla de análisis, en tanto que permitirá identificar aquellos elementos que pueden excluirse en análisis futuros.

\section{RESUltados}

Partiendo de las valoraciones realizadas por los tres observadores que participaron en el trabajo de campo puede afirmarse que, en líneas generales, la distribución espacial de todos los museos analizados es aceptable. Cabe señalar, no obstante, que en este ámbito el tipo de edificio resulta determinante y puede dificultar el uso de criterios estandarizados. Esto se debe a que no puede evaluarse de la misma manera un edificio reconvertido y un edificio de nueva planta creado ad hoc para albergar un museo.

Figura 1. Valoración global del espacio museal

\section{Valoración global del espacio museal}

\section{Espacios suficientes para el desarrollo de las actividades \\ Itinerarios bien señalizados}

Distribución coherente de los espacios

Espacios definidos

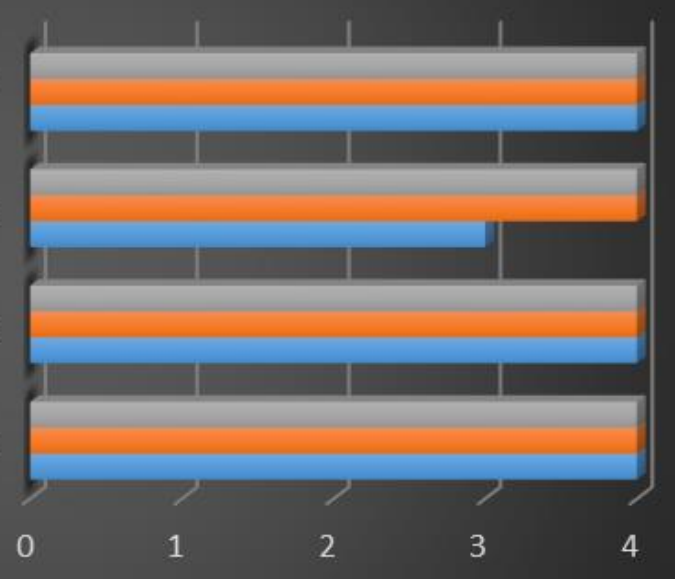

nObservador 1 Observador 2 Observador 3 (Novel)

Fuente: Elaboración propia a partir de los datos aportados por los investigadores.

En la muestra encontramos dos casos paradigmáticos de esta situación: por un lado, el Museo Etnográfico del Oriente, que reutiliza edificios de los siglos XVIII-XIX de carácter rural y doméstico, como viviendas campesinas, cuadras, pajares, etc.; y el Museo de la Siderurgia, emplazado en una antigua torre de refrigeración de la fábrica siderúrgica Duro Felguera. En estos museos cobran mayor relevancia aquellos indicadores que se vinculan con la gestión del espacio disponible, como la señalética (marcadores de itinerarios, planos, identificación de espacios...) y el papel de los educadores (ges- 
tión del comportamiento, distribución de los grupos de visitantes, uso de los recursos...), frente a otros más estandarizados como la amplitud o la presencia de espacios temáticos bien delimitados.

Teniendo en cuenta lo anterior, se ha observado que todos los museos mantienen una coherencia clara entre el espacio museal y los contenidos que se quieren transmitir, y no se han hallado problemas de espacio que afecten al desarrollo de las visitas. En cuanto a la información sobre los itinerarios, se trata de uno de los indicadores que se cumplen parcialmente. No necesariamente es un aspecto negativo, en tanto que no se trata de museos excesivamente grandes donde la información sobre dónde se encuentra el visitante o qué dirección tomar sea imprescindible; además, los museos cuentan con folletos de mano que incluyen planos e información básica sobre la distribución espacial. Pero conviene tener presente que ofrecer a la entrada del museo una síntesis sobre los contenidos del museo puede ser útil para organizar mentalmente la visita, lo cual resulta útil para incrementar la eficacia comunicativa del discurso museográfico (Bitgood, 2006). Solo se ha observado un ejemplo que se aproxima a este nivel deseable: el Museo del Ferrocarril de Asturias, que cuenta en la entrada con un gran panel cronológico que ordena los principales hitos en la historia ferroviaria. El panel puede funcionar como una introducción general a la temática que aborda el museo, aunque no profundiza en los contenidos museales. Pese a todo, se ha considerado que ninguno de los museos observados presenta problemas graves de circulación por las salas, de modo que los procesos comunicativos no se ven afectados en este sentido.

Figura 2. Valoración global de los objetos y la información textual

\section{Valoración global de los objetos y la información textual}

Recursos gráficos de los paneles

Información textual de los paneles

Situación y tipografía de los paneles

Información textual de las cartelas

Situación y tipografía de las cartelas

Disposición clara, sin sensación de abigarramiento

Objetos representativos

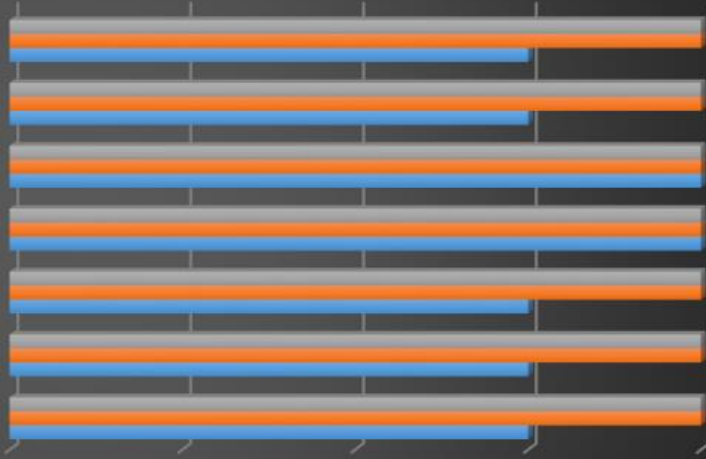

0

1

2

3

Fuente: Elaboración propia a partir de los datos aportados por los investigadores.

Con respecto a los objetos y la información textual y gráfica, se trata de uno de los ámbitos donde han aparecido mayores discrepancias entre los observadores con experiencia y el observador novel. El observador novel otorgó una valoración más baja en algunos museos donde la cantidad de objetos expuestos y la información textual es más importante, especialmente el Museo del Ferrocarril, el Parque de la Prehistoria y el Museo Marítimo, escribiendo en su diario de campo que «el volumen de información puede repercutir negativamente en la eficacia comunicativa». Es cierto que en estos casos 
existe una cantidad nada desdeñable de información textual (Museo del Ferrocarril), se emplea en ocasiones un lenguaje demasiado técnico (Parque de la Prehistoria) y en algunos puntos la cantidad de objetos puede dar a priori una sensación de abigarramiento (Museo Marítimo).

Sin embargo -y en este punto es donde aparecen las discrepancias-, los observadores con experiencia previa valoraron estos indicadores considerando el papel que el personal de los museos y los docentes pueden desempeñar seleccionando y adaptando esa información a los visitantes. Así, concedieron mayor importancia a la perspectiva cualitativa (tipo de contenidos) que a la cuantitativa (cantidad de contenidos). Curiosamente, el grado de acuerdo entre los observadores fue mayor en los museos donde la cantidad de información textual y gráfica es más limitada, como el Museo de la Siderurgia y el Museo Etnográfico del Oriente. Cabe destacar que en estos casos el observador novel ha percibido de forma más clara la interrelación entre la información museográfica y las explicaciones de los educadores, valorándolas conjuntamente al igual que los observadores con experiencia. Este hecho plantea una conclusión interesante: en cierto modo, en aquellos museos que disponen de un mayor número de objetos e información textual y gráfica, la museografía parece entrar en competencia con el papel de los educadores. En otras palabras, desde un punto de vista comunicativo, se valora positivamente que el papel de los educadores sea el de ampliar y/o complementar la información que proporciona la museografía, y no tanto resumirla o sintetizarla. Se trata de una tendencia creciente que puede observarse en el Centro de Arte Rupestre de Tito Bustillo, de reciente construcción, que cuenta con una museografía muy cuidada que concede un mayor peso al apartado visual, exponiendo únicamente los objetos más significativos y paneles que incluyen textos cortos pero suficientes y rigurosos cuya plena eficacia comunicativa depende en buena medida de las explicaciones de los educadores.

$\mathrm{Al}$ margen de estas consideraciones, no se han observado problemas en el diseño de los recursos textuales y gráficos en los museos analizados. Exceptuando lo comentado anteriormente, ninguno de los observadores señaló más deficiencias relacionadas con la extensión y complejidad de los textos, la tipografía o la ubicación de los paneles y demás recursos como maquetas o audiovisuales. Únicamente, en relación con estos últimos, coinciden en señalar dos problemas: el primero deriva de la rápida obsolescencia en el ámbito audiovisual. Así, en las Termas Romanas de Campo Valdés se expone un documental sobre el yacimiento y el museo. El planteamiento y los contenidos que aborda son adecuados, pero la calidad de imagen y de sonido se resienten por el paso de los años (el documental aún habla de Pesetas), lo cual, aunque didácticamente no tiene consecuencias, puede restarle eficacia comunicativa al reducir su atractivo visual. El segundo problema que se ha señalado es el de la reproducción automática e ininterrumpida. En efecto, en algunos casos los educadores se vieron obligados a paralizar la visita esperando a que la retransmisión multimedia se reiniciara o, en el peor de los casos, tuvieron que pasarla por alto. A este respecto, sería interesante contar con algún mecanismo para poder reiniciar la proyección manualmente; un recurso sencillo pero muy útil para evitar este problema. 
Figura 3. Valoración global de la intervención del/a educador/a

\section{Valoración global de la intervención del/a educador/a}

Se muestra seguro/a en sus explicaciones

Se muestra seguro/a al responder a las preguntas

Formula preguntas para fomentar la participación

Realimenta su explicación con las aportaciones de los..

Gestión del comportamiento de los estudiantes

Utiliza los paneles para apoyar su explicación

Utiliza los recursos complementarios

Adapta el discurso a la edad de los participantes

Concede un tiempo después de cada explicación

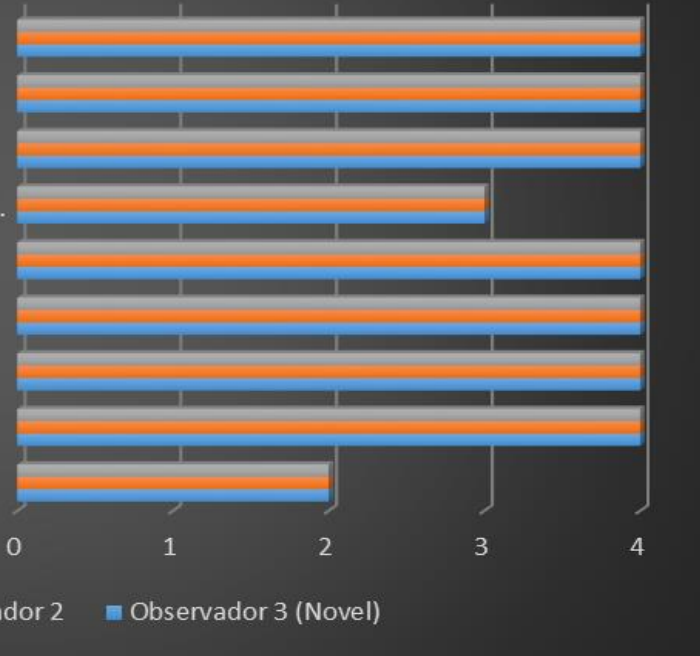

Fuente: Elaboración propia a partir de los datos aportados por los investigadores.

En lo referente a la dimensión humana de la comunicación en el museo, para su valoración se realizaron un total de 40 sesiones de seguimiento de visitas guiadas, con una media de 21 estudiantes (843 estudiantes en total) y dos docentes por grupo que abarcaban desde $1 .^{\circ}$ de Primaria hasta $2 .^{\circ}$ de Bachillerato. El total de educadores observados fue de 18.

El primer aspecto destacable es que, a través del trabajo se campo, se ha constatado que desde los museos existe un interés común por rechazar el modelo de comunicación unidireccional. De todos los casos analizados, inferimos que en el diseño de las visitas se contempla la formulación de preguntas a los visitantes, buscando establecer un diálogo inspirado en la mayéutica socrática. Asimismo, los educadores observados mostraron seguridad tanto en sus explicaciones, como a la hora de integrar en su discurso las aportaciones de los estudiantes, aunque este último indicador se ha valorado como cumplido parcialmente por las escasas aportaciones de los estudiantes. De igual forma, se realiza un uso adecuado de los recursos como las maquetas, los paneles y los audiovisuales, que son utilizados por los educadores para ilustrar su explicación. En cuanto al lenguaje y otros recursos comunicativos (entonación, gesticulación, ritmos...), cabe señalar que se adaptan convenientemente a la edad de los visitantes, graduando la complejidad en función del nivel educativo. Finalmente, solo uno de los indicadores ha sido valorado como no cumplido: el referido a la concesión de un tiempo después de cada explicación para que los visitantes puedan observar de forma autónoma los objetos y paneles sobre los que ha versado la explicación del educador. Aunque conviene tener presente que en esta situación influyen factores como las limitaciones de tiempo, ya sea por parte de las escuelas, o por las necesidades del museo de atender a más visitantes. 
MIGUEL ÁNGEL SUÁREZ SUÁREZ, ROSER CALAF MASACHS y M. ${ }^{a}$ DEL CARMEN FERNÁNDEZ RUBIO LA COMUNICACIÓN DEL PATRIMONIO: VALORACIÓN DE LOS PROCESOS COMUNICATIVOS EN MUSEOS DE ASTURIAS

Figura 4. Valoración global de la participación de los estudiantes

\section{Valoración global de la participación escolar (estudiantes)}

Muestran buen comportamiento durante la visita

Participan cuando el/a educador/a les formula preguntas

Formulan preguntas relacionadas con la explicación $\mathrm{del} / \mathrm{a}$ educador/a

Formulan preguntas sobre cuestiones no tratadas en la visita

Utilizan materiales creados en el aula

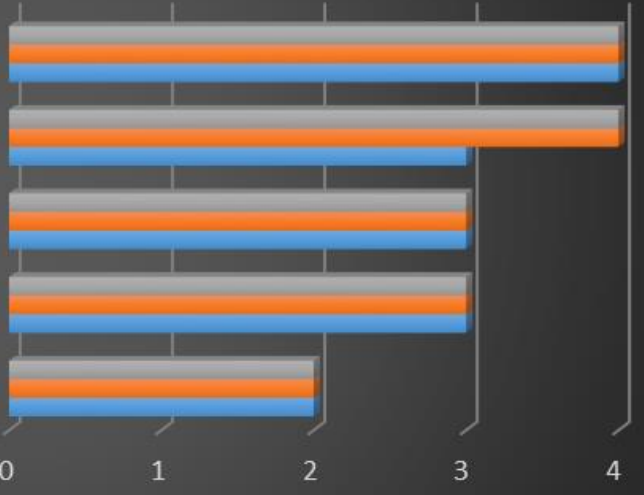

n Observador 1 Observador 2 Observador 3 (Novel)

Fuente: Elaboración propia a partir de los datos aportados por los investigadores.

Figura 5. Valoración global de la participación de los docentes

\section{Valoración global de la participación escolar (docentes)}

Acompaña al grupo y gestiona el comportamiento de los estudiantes

Realizan aportaciones puntuales vinculando la visita con el trabajo del aula

Introducen nuevos temas en la visita

Conceden un tiempo al final de la visita

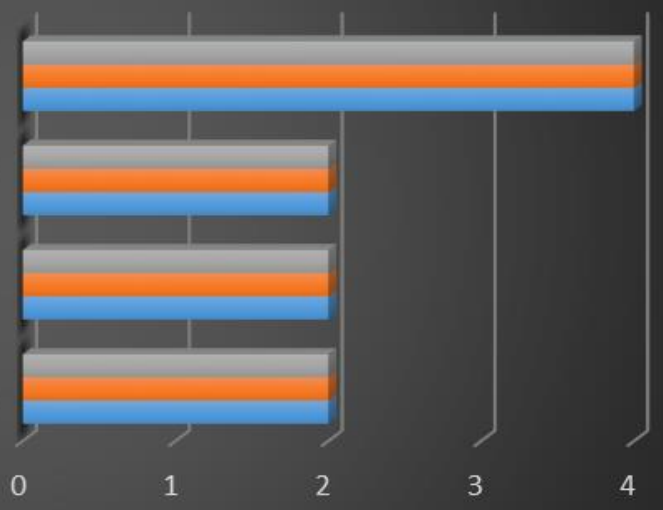

n Observador 1 abservador 2 Observador 3 (Novel)

Fuente: Elaboración propia a partir de los datos aportados por los investigadores. 
En cualquier caso, como puede apreciarse los indicadores con una valoración más baja se corresponden con la participación escolar. Es cierto que no se han observado problemas de comportamiento y que los escolares suelen participar cuando el educador les formula preguntas. Sin embargo, son los demás indicadores los que cobran mayor relevancia dentro de lo que consideramos la situación deseable, que como se ha comentado, es la del diálogo necesario entre la escuela y el museo. Primeramente, se ha observado que, por lo general, los estudiantes no suelen formular preguntas por iniciativa propia.

Aquí existen diferencias en función del nivel educativo: los más jóvenes se muestran más activos y participativos, sobre todo los estudiantes de centros fidelizados (aquellos que realizan la visita todos los años), que a menudo suelen integrar la visita dentro de un proyecto más amplio relacionado con la temática del museo; en cambio, la participación decrece hasta casi desaparecer a medida que se avanza de nivel y etapa educativa. La fidelización también influye en la participación de los docentes; así, aquellos que visitan con frecuencia el museo suelen realizar aportaciones que vinculan las explicaciones del educador patrimonial con otros contenidos impartidos o que se van a impartir en el aula. De cualquier forma, solo se han observado 7 casos, por lo que la situación dista de ser la idónea. Finalmente, no se ha observado en ningún caso que los estudiantes llevaran materiales elaborados ad hoc en el aula para utilizar durante la visita.

\section{CONCLUSIÓN}

La comunicación del patrimonio es un proceso complejo que abarca múltiples realidades, tiene lugar en contextos muy diversos y se dirige a un público muy heterogéneo. Por ello, no resulta sencillo definir qué elementos intervienen en su desarrollo y qué criterios deben contemplarse para su análisis. En este trabajo se ha presentado una propuesta de valoración para el ámbito museal y su relación con las escuelas, partiendo de la necesidad de entender la comunicación en el museo como el fruto de un diálogo entre las dos instituciones.

En líneas generales, la información que transmiten los museos analizados no plantea problemas desde el punto de vista comunicativo. La distribución espacial es adecuada, especialmente en aquellos museos que han debido readaptar edificios preexistentes salvando las limitaciones lógicas que ello imponte. Y de igual forma, tanto la selección de los objetos, como la información textual que los acompaña responden a un planteamiento meditado y consciente del público al que se dirige. Empero, en algunos museos se ha observado un exceso de información, bien textual, bien objetual, que potencialmente puede saturar al visitante y reducir la eficacia comunicativa. Aunque la labor de los educadores, seleccionando y sintetizando la información, limita estos problemas, se trata de una cuestión a tener en cuenta, sobre todo respecto al público que visita libremente el museo.

A pesar de lo anterior, la eficacia comunicativa se ve limitada por la ausencia de un verdadero diálogo entre el museo y la escuela, que en este caso se corresponde con la integración de la visita en el desarrollo curricular. Si bien la participación escolar suele ser satisfactoria en términos de comportamiento, así como respondiendo juiciosamente a las preguntas formuladas por el educador del museo, no se han observado otras circunstancias que podrían indicar que la escuela está desempeñando su papel en ese diálogo.

Pese a todo es de justicia señalar que, según informaron los responsables de los museos analizados, sí que existen grupos de escolares que utilizan materiales creados ad hoc en el aula para utilizar durante la visita, mostrándose mucho más activos de lo que se ha podido observar durante nuestras sesiones de campo. Esta situación concuerda con los resultados de otros estudios donde, en efecto, pudieron observarse grupos de escolares que acudían al museo como parte de un proyecto más amplio

(C) Ediciones Universidad de Salamanca / CC BY - NC ND Fonseca, Journal of Communication, n. 14, 2017, pp. 131-146 
(Suárez, Calaf y San Fabián, 2014). En esos casos se puso de manifiesto la importancia de poseer unos objetivos previamente definidos (Screven, 1993), lo que motivó una participación escolar mucho más intensa que introdujo nuevos temas en el desarrollo de la visita. De ahí que la participación escolar, que sin duda está siguiendo una tendencia favorable, aunque todavía insuficiente, constituya un elemento básico sin el cual, la comunicación en el museo nunca podrá ser plenamente eficaz.

\section{BibLIOGRAFÍA}

Angrosino, M. (2012). Etnografia y observación participante en investigación cualitativa. Madrid: Morata.

Asensio, M., Asenjo, E. y Rodríguez-Moneo, M. (2011). De la discusión teórica de los tipos de aprendizaje informal y motivado, dos etiquetas distintas y un solo aprendizaje verdadero. En M. Asensio y E. Asenjo (Eds.), Lazos de luz azul. Museos y tecnologías 1, 2 y 3.0 (pp. 49-78). Barcelona: UOC.

Banks, M. (2010). Los datos visuales en investigación cualitativa. Madrid: Morata.

Bitgood, S. (1992). The ABCs of Label Design. En S. Bitgood, A. Benefield y D. Patterson (Eds.), Visitor studies: Theory, research and practice, vol. 3 (pp. 115-129). Jakcsonville: Centre for Social Design.

Bitgood, S. (2006). An analysis of visitor circulation movement patterns and the general value principle. Curator, 49 , 463-475.

Bitgood, S. (2013). Attention and value: Keys to understanding museum visitors. New York: Routledge.

Bitgood, S. (2014). Understanding the importance of visitor navigation. InterpNews, 3, 3-5.

Calaf, R. (2009). Didáctica del patrimonio. Epistemología, metodología y estudio de casos. Gijón: Ediciones Trea.

Calaf, R. y Fontal, O. (2010). Cómo enseñar arte en la escuela. Madrid: Síntesis.

Calaf, R. y Suárez, M. Á. (2011). Una mirada panorámica sobre los museos de Asturias: entre el espacio real y el espacio virtual. Her\&Mus (Heritage \& Museography), 7, 19-30.

Calaf, R., San Fabián, J. L., Suárez, M. Á. y Martín, M. (2016). Un diseño de investigación para desvelar criterios de calidad en programas educativos de museos. En R. Calaf y M. Á. Suárez (Coords.), Acción educativa en museos. Su calidad desde la evaluación cualitativa (pp. 25-45). Gijón: Ediciones Trea.

Cordón, D. y González, D. (2016). Museos y comunicación: los nuevos medios como herramienta de diálogo y sociabilidad de la institución. El uso de Twitter por el Museo del Prado, Museo Thyssen-Bornemisza y Museo Reina Sofía. Fonseca, Journal of Communication, 12, 149-165.

Cuenca, J. M. ${ }^{a}$ y Estepa, J. (2004). La didáctica del patrimonio en Internet. Análisis de páginas web elaboradas por centros de interpretación del patrimonio cultural. En M. I. Vera y D. Pérez (Coords.), Formación de la ciudadanía: las TICs y los nuevos problemas (pp. 1-12). Alicante: Asociación Universitaria de Profesores de Didáctica de las Ciencias Sociales.

Davallon, J. (1999). L'exposition à l'oeuvre. Stratégies de communication et médiation symbolique. Paris: L'Harmattan.

De Troyer, V. (Coord.) (2005). Heritage in the classroom. A practical manual for teachers. Bruxelles: Het Gemeenschapsonderwijs. Disponible en: http://www.dvzu.si/uploads/1/3/5/1/13519427/hereduc complete book.pdf (Recuperado el 01/10/2016).

Eco, U. (1962). La obra abierta. Barcelona: Ariel.

Eco, U. (2000). Tratado de semiótica general. Barcelona: Lumen.

Estepa, J. (Coord.) (2013). La educación patrimonial en la escuela y el museo: investigación y experiencias. Huelva: Servicio de Publicaciones de la Universidad de Huelva.

Flick, U. (2004). Introducción a la investigación cualitativa. Madrid: Morata. 
Fontal, O. (2004). Las webs: complementos y extensiones de los museos. En R. Calaf y O. Fontal (Coords.), Miradas al patrimonio (pp. 181-200). Gijón: Ediciones Trea.

Gibbs, G. (2012). El análisis de datos cualitativos en Investigación Cualitativa. Madrid: Morata.

Gutiérrez, S. y Calaf, R. (2013). La evaluación pedagógica: una realidad en el museo. Pulso: Revista de Educación, 36, 37-53.

Ibáñez, Á., Correa, J. M. y Jiménez, E. (2003). Museos e internet en el País Vasco: ¿Contextos de aprendizaje? En Ballesteros, E. et al. (Coords.), Elpatrimonio y la didáctica de las Ciencias Sociales (pp. 429-441). Cuenca: Asociación Universitaria de Profesores de Didáctica de las Ciencias Sociales.

Martín Cáceres, M. (2012). La educación y la comunicación patrimonial: una mirada desde el Museo de Huelva. Tesis doctoral. Huelva: Universidad de Huelva.

Martín Cáceres, M. y Cuenca, J. M.a (2011). La enseñanza y el aprendizaje del patrimonio en los museos: la perspectiva de los gestores. Revista de Psicodidáctica, 16(1), 99-122.

McMillan, J. H. y Schumacher, S. (2005). Investigación educativa. Madrid: Pearson Educación.

Screven, C. (1976). Exhibit Evaluation: a goal referenced approach. Curator, 19, 109-137.

Screven, C. (1986). Exhibitions and information centers: some principles and approaches. Curator, 29, 109-137.

Screven, C. (1992). Motivating visitor to read labels. ILVS Review, 2(2), 183-211.

Screven, C. (1993). Museums and informal education. CMS Bulletin, 1(1). Disponible en http://www.infed.org/archives/e-texts/screven-museums.htm (Recuperado el 05/10/2016).

Shettel, H. (1988). Status report on museum evaluation: an instrospective retrospective. ILVS Review, 1(1), 14-23.

Shettel, H. (1989). Evaluation in museums: a short history of a short history. En D. Uzzell (Dir.), Heritage Interpretation. Vol. II: Visitor experience (pp. 48-62). London: Belhaven.

Suárez, M. Á.; Calaf, R. y San Fabián, J. L. (2014). Aprender historia a través del patrimonio. Los casos del Museo del Ferrocarril de Asturias y del Museo de la Inmigración de Cataluña. Revista de Educación, 365, 38-66.

Suárez, M. Á., Gutiérrez, S., Calaf, R. y San Fabián, J. L. (2013). La evaluación de la acción educativa museal: una herramienta para el análisis cualitativo. Clio: History and History teaching, 39, 1-45.

Suárez, M. Á. (2014). ¿Aprender el patrimonio o aprender con el patrimonio? En R. Calaf, M. Á. Suárez y S. Gutiérrez, La evaluación de la acción cultural en museos (pp. 35-50). Gijón: Ediciones Trea. 
Anexo: Plantilla de análisis

\begin{tabular}{|c|c|c|c|c|c|c|}
\hline ÁMBITO & INDICADOR & DESCRIPTOR & 1 & 2 & 3 & $4^{*}$ \\
\hline \multirow{5}{*}{ 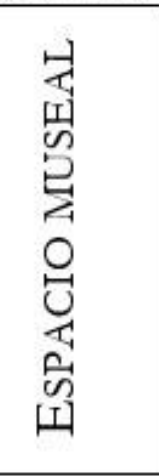 } & \multirow{5}{*}{$\begin{array}{l}\text { DISTRIBUCIÓN } \\
\text { ESPACIAL Y } \\
\text { ADECUACIÓN DE } \\
\text { LOS ESPACIOS }\end{array}$} & $\begin{array}{l}\text { Existen espacios diferenciados y estructurados por temáticas o } \\
\text { ámbitos concretos. }\end{array}$ & & & & \\
\hline & & $\begin{array}{l}\text { Los distintos espacios están relacionados entre sí sigusendo una } \\
\text { lógica argumental coherente (progresión local-global, } \\
\text { progresión cronológica, introducción y desarrollo del tema, } \\
\text { preguntas clave...). }\end{array}$ & & & & \\
\hline & & $\begin{array}{l}\text { Los distintos espacios o ámbitos están bien señalizados y son } \\
\text { fácilmente identificables mediante indicadores o cualqujer otro } \\
\text { distintivo. }\end{array}$ & & & & \\
\hline & & $\begin{array}{l}\text { Existe uno o varios itinerarios prefijados y bien señalizados que } \\
\text { hacen posible el recorrido autónomo por el museo. }\end{array}$ & & & & \\
\hline & & $\begin{array}{l}\text { El museo dispone de espacios adecuados en cuanto a amplitud } \\
\text { y estado de las instalaciones para la realización de las } \\
\text { actividades. }\end{array}$ & & & & \\
\hline \multirow{17}{*}{ 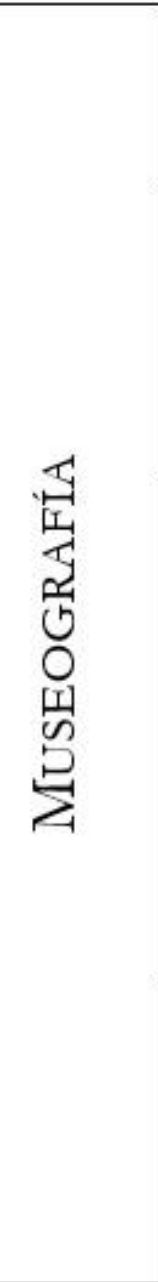 } & \multirow[t]{3}{*}{ OBJETOS } & Se muestran objetos representativos de la temática del museo. & & & & \\
\hline & & $\begin{array}{l}\text { La disposición de los objetos es clara, sin sensación de } \\
\text { abigarramiento } \mathrm{V} / \text { o aleatoriedad en su colocación }\end{array}$ & & & & \\
\hline & & $\begin{array}{l}\text { Los objetos están estructurados por áreas o ámbitos que } \\
\text { facilitan su identificación y contextualización. }\end{array}$ & & & & \\
\hline & \multirow[t]{4}{*}{ CARTELAS } & $\begin{array}{l}\text { Las cartelas se encuentran en un lugar visible y a una altura } \\
\text { adecuada sin interferir en la presentación de los objetos. }\end{array}$ & & & & \\
\hline & & $\begin{array}{l}\text { Las cartelas utilizan una tipografia adecuada en cuanto a } \\
\text { tamaño y color de las letras, facilitando la lectura. }\end{array}$ & & & & \\
\hline & & $\begin{array}{l}\text { Las cartelas identifican perfectamente el nombre/tipologia de } \\
\text { los objetos expuestos. }\end{array}$ & & & & \\
\hline & & $\begin{array}{l}\text { Las cartelas incluyen otras informaciones complementarias } \\
\text { como la funcionalidad, los materiales, etc. de los objetos } \\
\text { expuestos. }\end{array}$ & & & & \\
\hline & \multirow[t]{6}{*}{ PANELES } & $\begin{array}{l}\text { Los paneles se localizan en lugares visibles } y \text { a una altura } \\
\text { adecuada, sin interferir en el tránsito por las salas ni } \\
\text { obstaculizar la visualizacion de los objetos. }\end{array}$ & & & & \\
\hline & & $\begin{array}{l}\text { La ubicación de los paneles mantiene una coherencia entre su } \\
\text { contenido y los objetos/ámbitos a los que hace referencia. }\end{array}$ & & & & \\
\hline & & $\begin{array}{l}\text { Los paneles son fáciles de leer al incluir una tipografia adecuada } \\
\text { en cuanto a tamaño } y \text { color de las letras. }\end{array}$ & & & & \\
\hline & & $\begin{array}{l}\text { Los paneles presentan textos sintéticos pero suficientes para } \\
\text { abordar los contenidos que pretenden explicar. }\end{array}$ & & & & \\
\hline & & $\begin{array}{l}\text { Los textos de los paneles están redactados con un lenguaje } \\
\text { sencillo pero riguroso, facilitando la comprensión de } \\
\text { conceptos técnicos o académicos. }\end{array}$ & & & & \\
\hline & & $\begin{array}{l}\text { Los paneles incorporan elementos gráficos que complementan } \\
\text { la información textual (esquemas, diagramas, fotografias, } \\
\text { mapas, representaciones ideales...). }\end{array}$ & & & & \\
\hline & \multirow[t]{4}{*}{ AUDIOVISUALES } & $\begin{array}{l}\text { Los audiovisuales son concisos y su contenido es coherente } \\
\text { con el lugar del museo en que se encuentran. }\end{array}$ & & & & \\
\hline & & $\begin{array}{l}\text { Los audiovisuales se integran perfectamente en la museografia } \\
\text { y no interfieren ni dificultan el recorrido por el espacio museal. }\end{array}$ & & & & \\
\hline & & $\begin{array}{l}\text { Aportan datos relevantes para ampliar la información que } \\
\text { puede desprenderse de los objetos y paneles. }\end{array}$ & & & & \\
\hline & & $\begin{array}{l}\text { Poseen un componente interactivo que ofrece al visitante y al } \\
\text { educador/a un mínimo grado de control sobre la información } \\
\text { (posibilidad de reiniciar, pausar, etc.). }\end{array}$ & & & & \\
\hline
\end{tabular}




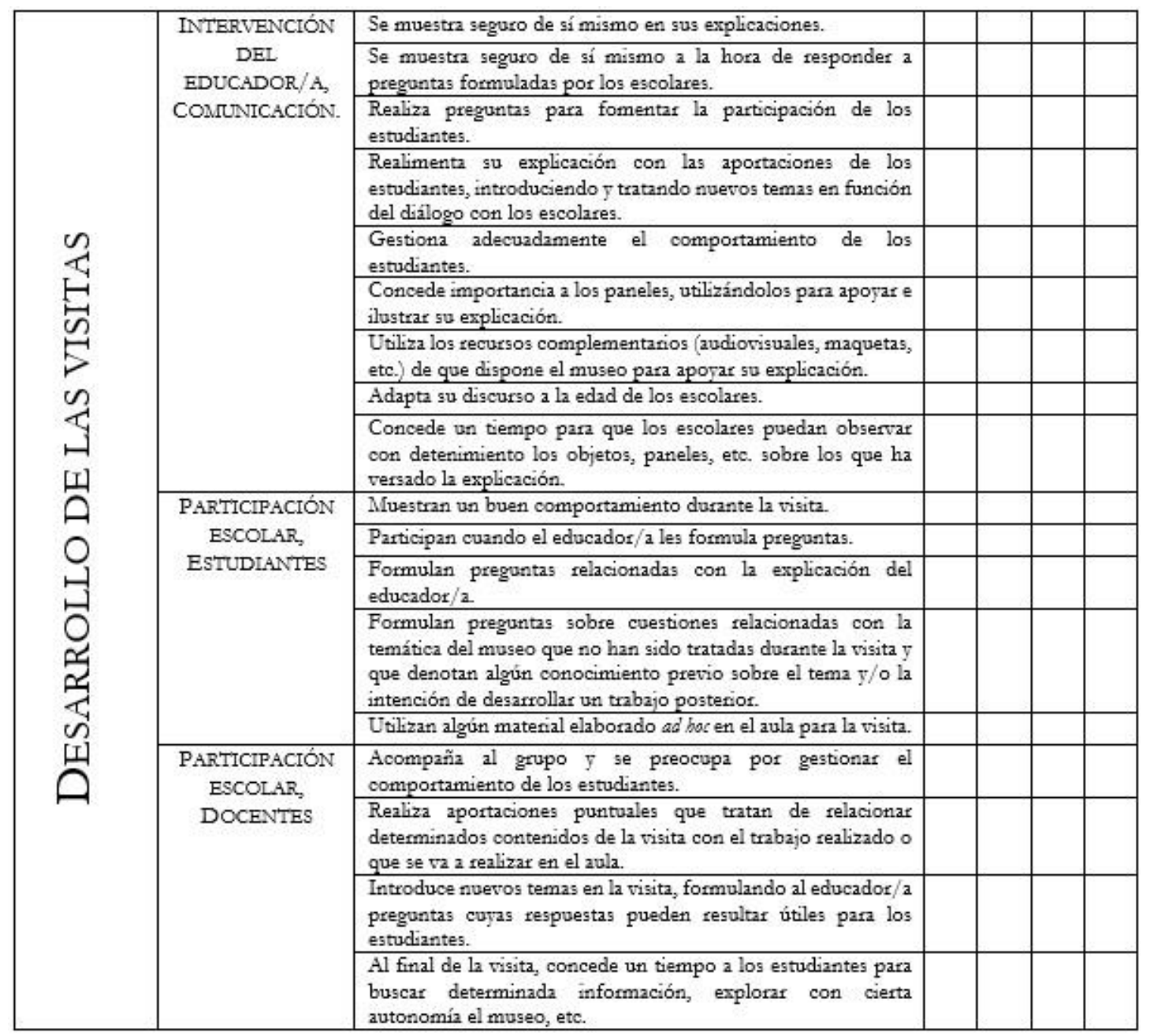

